\title{
The effect of hypothyroidism on referential background metabolic activity on ${ }^{18}$ F-FDG PET/CT
}

\author{
Pei Yang", Qiuping Fan", Huawei Cai, Rong Tian, Minggang Su \\ Department of Nuclear Medicine, West China Hospital, Sichuan University, Chengdu, China
}

\#These authors contributed equally to this work.

Correspondence to: Minggang Su, MD. Department of Nuclear Medicine, West China Hospital, Sichuan University, 37 Guoxue Alley, Chengdu 610041, China. Email: suminggang@sina.com.

Background: Background uptake activity is used as a reference to assess treatment response by positron emission tomography-computed tomography (PET/CT) with 2-deoxy-2-[F-18]fluoro-D-glucose $\left({ }^{18} \mathrm{~F}-\mathrm{FDG}\right)$. Prior studies have reported decreased liver and increased muscle ${ }^{18} \mathrm{~F}-\mathrm{FDG}$ uptake in patients with hyperthyroidism. We hypothesized that hyperthyroidism and hypothyroidism might have inverse effects on ${ }^{18}$ F-FDG uptake on PET/CT.

Methods: We recruited 36 patients with hypothyroidism and 36 age and gender-matched euthyroid participants. We recorded patient factors and background mean standardized uptake values normalized by lean body mass from the aortic blood pool, liver, and muscle. We compared the patient factors and background standardized uptake values normalized by lean body mass between hypothyroidism patients and the controls. We performed a multivariate analysis to determine the best predictors of the 3 different background standardized uptake values normalized by lean body mass.

Results: Patients with hypothyroidism had higher liver standardized uptake values normalized by lean body mass $(1.77 \pm 0.33$ vs. $1.58 \pm 0.26, \mathrm{P}=0.009)$ and aortic blood-pool standardized uptake values normalized by lean body mass $(1.21 \pm 0.22$ vs. $1.11 \pm 0.20, \mathrm{P}=0.040)$ than the controls. In contrast, the muscle standardized uptake value normalized by lean body mass $(0.50 \pm 0.09$ vs. $0.54 \pm 0.09, \mathrm{P}=0.044)$ of the patients with hypothyroidism was lower than that of the controls. The serum level of thyroid-stimulating hormone was an independent predictor of liver standardized uptake values normalized by lean body mass $(\beta=0.356, P<0.001)$ and bloodpool standardized uptake values normalized by lean body mass $(\beta=0.288, \mathrm{P}=0.001)$. The serum level of free triiodothyronine was an independent predictor of muscle standardized uptake values normalized by lean body mass $(\beta=0.310, \mathrm{P}=0.002)$.

Conclusions: PET/CT scans showed that hypothyroidism patients had increased liver and blood-pool ${ }^{18}$ F-FDG uptake and decreased skeletal muscle ${ }^{18}$ F-FDG uptake compared with euthyroid individuals. These alterations should be noted when a metabolic response to cancer treatment on PET/CT is determined.

Keywords: 2-deoxy-2-[F-18]fluoro- D-glucose $\left({ }^{18} \mathrm{~F}\right.$-FDG); positron emission tomography-computed tomography (PET/CT); liver; blood pool; hypothyroidism

Submitted Nov 27, 2020. Accepted for publication Apr 01, 2021.

doi: $10.21037 /$ qims-20-1310

View this article at: http://dx.doi.org/10.21037/qims-20-1310

\section{Introduction}

Positron emission tomography-computed tomography (PET/CT) with 2-deoxy-2-[F-18]fluoro-D-glucose $\left({ }^{18} \mathrm{~F}-\mathrm{FDG}\right)$ is widely used to evaluate responses to cancer treatment. In clinical practice, the standardized uptake value (SUV) of background tissues such as the aortic 
blood pool and the liver is often used as references for accurate treatment response interpretation (1-3). However, variations in biological factors such as blood glucose level and incubation time (time from FDG injection to PET/ CT scan) can affect the ${ }^{18} \mathrm{~F}$-FDG uptake in these regions (4-7). This can be problematic when a metabolic response is defined, especially for quantitative evaluation, based on the PET Response Criteria in Solid Tumors (PERCIST). The PERCIST requires that a measurable tumor uptake is determined relative to the activity of a background (1-3).

Prior studies reported that ${ }^{18} \mathrm{~F}-\mathrm{FDG}$ uptake was decreased in the liver and increased in the muscles of patients with hyperthyroidism, likely due to increased endogenous liver glucose production and increased heat production by the muscles (8-10). Hypothyroidism is much more common than hyperthyroidism, especially in the aging population, in patients treated with certain drugs (lithium, amiodarone, tyrosine kinase inhibitors, immune checkpoint inhibitors, etc.), and in patients that have received neck radiotherapy (11-13). Theoretically, individuals with hypothyroidism should have increased liver glycogenesis but decreased skeletal muscle glucose uptake compared with individuals with normal thyroid function (14). Therefore, we hypothesized that the pattern of ${ }^{18} \mathrm{~F}$-FDG uptake on PET/CT in patients with hypothyroidism would be the inverse of that in hyperthyroidism patients. Hypothyroidism should be noted before ${ }^{18} \mathrm{~F}-\mathrm{FDG}$ PET/CT is used to evaluate cancer treatment response if the hypothesis is correct. To test our hypothesis, we characterized the referential background ${ }^{18} \mathrm{~F}-\mathrm{FDG}$ uptakes in patients with hypothyroidism and compared them with those with normal thyroid function.

\section{Methods}

This study was approved by the Institutional Review Board of the West China Hospital and was conducted according to the Declaration of Helsinki guidelines. The requirement to obtain written, informed patient consent was waived because the study was retrospective.

\section{Patient selection}

A total of 36 patients with hypothyroidism who underwent PET/CT scans from June 2012 to December 2018 and met the following inclusion and exclusion criteria were involved in this retrospective study. The inclusion criteria were as follows: age higher than 18 years, thyroid status confirmed by a laboratory test within 2 days of the PET/ CT scan, normal liver and renal function, and normal blood cell count. Individuals with diabetes, a history of chemotherapy, tumor involvement of the aorta, liver, or muscle, history of liver radiotherapy, steatosis, hepatitis, or ${ }^{18} \mathrm{~F}$-FDG extravasation at the injection time were excluded from the study. Hypothyroidism was defined based on a serum thyroid-stimulating hormone (TSH) level higher than $4.20 \mathrm{mU} / \mathrm{L}$ and free thyroxine concentrations below the reference range (12.0-22.0 mU/L). All patients had overt iatrogenic hypothyroidism, and 35 patients received total thyroidectomy because of thyroid cancer, and they all withdrew levothyroxine 2-3 weeks before PET/CT scans. The other 1 patient received radioiodine treatment due to Graves' disease.

Based on the 1:1 age-gender paring rules, we also enrolled 36 control individuals who underwent cancer screening during the same period and were found to be healthy with normal thyroid function. Patients with a serum TSH level from $0.27-4.20 \mathrm{mU} / \mathrm{L}$ were considered to have normal thyroid function. Serum TSH was measured using a time-resolved immunofluorometric assay (Anytest; Sym-Bio Lifescience Co. Ltd, Shanghai, China).

\section{PET/CT protocol}

All of the participants fasted for at least $6 \mathrm{~h}$ before receiving an injection of ${ }^{18} \mathrm{~F}$-FDG $(5.55 \mathrm{MBq} / \mathrm{kg})$. The participants' fasting blood glucose levels were all within the normal range (less than $7.0 \mathrm{mmol} / \mathrm{L}$ ). An attenuation CT scan was performed using a low-dose $(120 \mathrm{kV}, 40 \mathrm{mAs}$, slice thickness $5 \mathrm{~mm}$ ), a non-contrast protocol for attenuation and localization of abnormal ${ }^{18} \mathrm{~F}-\mathrm{FDG}$ activity. PET images were acquired from the mid-thigh to the skull base at a speed of 1.5 min per bed and reconstructed using a line-ofresponse row-action maximum likelihood algorithm. All of the scans were performed using a Gemini GXL PET/CT scanner (Philips, Netherlands).

\section{Measurements of background SUVs}

Background mean SUVs from the aortic blood pool, liver, and muscle were recorded. We calculated the aortic bloodpool SUV by drawing 3 circular regions of interest (ROIs) on 3 contiguous slices within the thoracic aorta's lumen, taking care not to include the vessel wall in the ROIs. We 
determined the liver SUV manually by placing a volume of interest with a diameter of $3 \mathrm{~cm}$ in the center of the right hepatic lobe (15). We determined the muscle SUV by selecting 3 circular ROIs on 3 contiguous slices in the erector spinae at the level of the $12^{\text {th }}$ thoracic vertebra, making sure the ROIs were within the margins of the muscle. We then computed normalized SUVs (SULs) that accounted for lean body mass (LBM) using the following formulas, where BMI is body mass index $\left(\mathrm{kg} / \mathrm{m}^{2}\right)(15)$.

$$
\begin{aligned}
& S U L=A c t_{V O I}(K B q / \mathrm{mL}) A c t_{\text {administered }}(M B q) / L B M(\mathrm{~kg}) \\
& L B M_{\text {male }}=9,270 \times \text { weight } /(6,680+216 \times \text { BIM }) \\
& L B M_{\text {female }}=9,270 \times \text { weight } /(8,780+244 \times B I M)
\end{aligned}
$$

\section{Statistical analysis}

Background SULs along with patient factors [age, height, weight, BMI, blood glucose level, LBM, injected ${ }^{18}$ F-FDG dose, incubation time, accumulated radioiodine dose in patients that received radioiodine treatment, serum TSH levels, free triiodothyronine (FT3) levels, and free thyroxine (FT4) levels)] were recorded. Because of a methodological issue with specimen dilution, we could not accurately measure serum TSH levels higher than $100 \mathrm{mU} / \mathrm{L}$, so we assigned serum TSH levels higher than $100 \mathrm{mU} / \mathrm{L}$ a value of $100 \mathrm{mU} / \mathrm{L}$. We used the mean \pm standard deviation (SD) for normal variables and the interquartile range P50 (P25, P75) for non-normal variables for descriptive statistics. We evaluated the normality of the data using the KolmogorovSmirnov test. We compared the background SULs and patient factors between the patients with hypothyroidism and the controls using the independent sample $t$-test or Mann-Whitney U-test. Then, we calculated the relative difference in each background SUL between patients with hypothyroidism and the controls. Subsequently, we examined associations between the background SULs and the other patient factors by performing Pearson's or Spearman's correlations. Finally, we performed a stepwise multivariate analysis to determine the best predictors of the 3 different background SULs. All statistical analyses were performed using SPSS 20.0 software (SPSS Inc., Chicago, Illinois, USA). $\mathrm{P}$ values less than 0.05 were considered statistically significant.

\section{Results}

\section{Patient characteristics}

A total of 72 participants matched for age and gender (mean age: $44.14 \pm 10.35$ years; 40 female, 32 male) were included. The SULs and patient factors were distributed normally, except for the TSH, FT3, and FT4 levels, accumulated radioiodine dose, incubation time, and LBM. There were no significant differences between the patients with hypothyroidism and the controls in terms of height, weight, BMI, injected ${ }^{18}$ F-FDG dose, blood glucose level, incubation time, or LBM. There were significant differences between the 2 groups in TSH, FT3, and FT4 levels $(\mathrm{P}<0.001$ for each factor; Table 1$)$.

\section{Background SULs}

The hypothyroidism patients had higher liver SUL (L-SUL) and blood-pool SUL (BP-SUL) than the controls. The L-SUL was $1.77 \pm 0.33$ for the hypothyroid group and $1.58 \pm 0.26$ for the euthyroid group $(\mathrm{P}=0.009)$. The BP-SUL was $1.21 \pm 0.22$ for hypothyroidism patients and $1.11 \pm 0.20$ for the controls $(\mathrm{P}=0.040)$. In contrast, the muscle SUL (M-SUL) was lower in the patients with hypothyroidism $(0.50 \pm 0.09)$ than in the controls $(0.54 \pm 0.09, \mathrm{P}=0.044)$. The detailed results are shown in Table 2, Figures 1,2.

\section{Bivariate correlation analysis of the background SULs and other factors}

All of the background SULs were positively correlated with gender, height, and LBM $(\mathrm{P}<0.01$ for each correlation; Table 3). L-SUL and BP-SUL were positively correlated with weight, ${ }^{18} \mathrm{~F}$-FDG dose, and TSH level $(\mathrm{P}<0.05$, for each correlation). Also, M-SUL was positively correlated with the FT3 and FT4 levels ( $\mathrm{P}<0.01$ for each correlation). By contrast, BP-SUL was negatively correlated with incubation time $(\mathrm{P}=0.002)$. We investigated the correlations between the accumulated radioiodine dose and each background SUL to determine if radioiodine impacted, but we found no correlations with this factor. The correlations between SULs and thyroid function are shown in Figure 3.

As muscle activity, and therefore muscle ${ }^{18} \mathrm{~F}-\mathrm{FDG}$ uptake may be partly dependent on muscular heat production, we took seasonal influences and the outside temperature 
Table 1 General characteristics of the study participants

\begin{tabular}{|c|c|c|c|c|}
\hline Characteristics & Hypothyroid & Euthyroid & $\mathrm{t}$ or $\mathrm{Z}$ value & $P$ value \\
\hline Age & $44.14 \pm 10.35$ & $44.14 \pm 10.35$ & 0.000 & 1.000 \\
\hline Height (cm) & $164.33 \pm 7.81$ & $163.5 \pm 8.68$ & 0.428 & 0.670 \\
\hline Weight (kg) & $64.50 \pm 13.27$ & $61.16 \pm 9.40$ & 1.241 & 0.219 \\
\hline FDG dose $(\mathrm{MBq})$ & $375.92 \pm 65.86$ & $357.42 \pm 55.87$ & 1.342 & 0.184 \\
\hline Blood glucose level (mmol/L) & $5.05 \pm 0.53$ & $5.29 \pm 0.51$ & -1.604 & 0.113 \\
\hline $\mathrm{LBM}^{*}$ & $40.81(36.87,54.63)$ & $39.51(36.07,52.23)$ & -0.569 & 0.570 \\
\hline Incubation time $(\mathrm{min})^{*}$ & $63.77(56.43,71.05)$ & $65.20(57.72,71.43)$ & -0.631 & 0.528 \\
\hline $\mathrm{FT}^{*}$ & $2.92(1.55,3.95)$ & $16.87(15.41,18.05)$ & -7.298 & $<0.001$ \\
\hline $\begin{array}{l}\text { Accumulated radioiodine dose } \\
\text { in DTC patients (MBq, } n=27 \text { ) }\end{array}$ & $5,550(3,700,7,400)$ & NA & NA & NA \\
\hline
\end{tabular}

$\mathrm{P}$ values were determined by two independent sample $t$-test and Mann-Whitney U-test between the patients with hypothyroidism and the controls. Factors labeled with * are expressed with the interquartile range P50 (P25, P75), because they were non-normal variables. The other factors were expressed with mean \pm standard deviation. BMI, body mass index; LBM, lean body mass; TSH, serum thyroidstimulating hormone (normal range is $0.27-4.20 \mathrm{mU} / \mathrm{L}$ ). Because of a methodological issue with specimen dilution, serum TSH levels higher than $100 \mathrm{mU} / \mathrm{L}$ could not be measured accurately, so levels higher than $100 \mathrm{mU} / \mathrm{L}$ were assigned a value of $100 \mathrm{mU} / \mathrm{L}$; FT3, serum free triiodothyronine (normal range is 3.6-7.5 mU/L); FT4, serum free thyroxine (normal range is 12.0-22.0 mU/L); DTC, differentiated thyroid cancer; NA, not available.

Table 2 SULs of the liver, aortic blood pool, and skeletal muscle in the patients and controls

\begin{tabular}{lccc}
\hline SULS & Hypothyroid & Euthyroid & P value \\
\hline L-SUL & $1.77 \pm 0.33(1.27-2.51)$ & $1.58 \pm 0.26(1.19-2.22)$ & 0.009 \\
BP-SUL & $1.21 \pm 0.22(0.87-1.70)$ & $1.11 \pm 0.20(0.67-1.69)$ & 0.040 \\
M-SUL & $0.50 \pm 0.09(0.31-0.84)$ & $0.54 \pm 0.09(0.38-0.80)$ & 0.044 \\
\hline
\end{tabular}

Numbers in parentheses are the maximum and minimum values. L-SUL, liver normalized standard uptake value; BP-SUL, aortic bloodpool normalized standard uptake value; M-SUL, muscle normalized standard uptake value.

on the scanning day into account. We found that the M-SUL was not correlated with the season and outside $\max / \mathrm{min}$ temperature. The detailed results are shown in Tables S1,S2.

\section{Multivariate linear regression of the background SULs and other patient factors}

After adjusting for all other significant factors that included gender, height, weight, ${ }^{18} \mathrm{~F}$-FDG dose, LBM, incubation time, TSH, FT3, and FT4 in the bivariate correlations using a stepwise multivariate analysis, we found that the TSH level was an independent predictor of L-SUL $(\beta=0.356, \mathrm{P}<0.001)$ and BP-SUL $(\beta=0.288, \mathrm{P}=0.001)$. In addition, we found that the FT3 level was an independent predictor of M-SUL ( $\beta=0.310, \mathrm{P}=0.002$; Table 4$)$.

\section{Discussion}

It is common in clinical practice to use PET/CT with background activity as a reference to assess the treatment response of lymphoma or solid cancers. A complete 


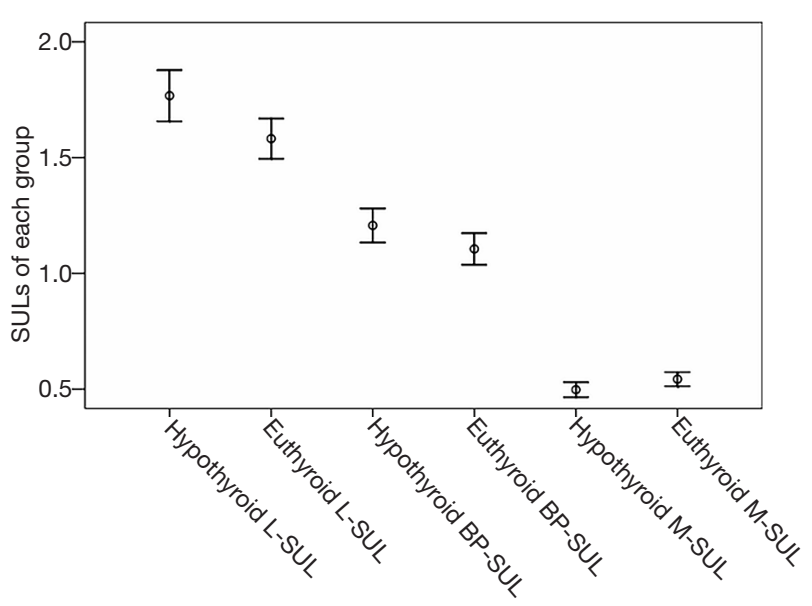

Figure 1 Comparisons of the liver, aortic blood-pool, and skeletal muscle SULs between patients with hypothyroidism and controls. The circles in the error bars represent the mean SUL of each background, and the bars represent the 95\% CI of the SULs of each group. SUL, standard uptake value normalized by lean body mass; L-SUL, liver normalized standard uptake value; BP-SUL, aortic blood-pool normalized standard uptake value; M-SUL, muscle normalized standard uptake value.

metabolic response (CMR) is determined if the lesion's residual activity is equal to or lower than that of the liver or blood pool (1-3). Accurate evaluation of the treatment response is important for prognosis prediction and for making decisions about the therapeutic strategy $(2,16)$. Both require a stable background activity, which is susceptible to many biological factors (4-6). Therefore, various factors must be checked before PET/CT results are used to interpret a treatment response. Prior studies reported the effects of hyperthyroidism on liver and muscle ${ }^{18} \mathrm{~F}-\mathrm{FDG}$ uptake (8-10). However, there is little information about the effects of hypothyroidism on background ${ }^{18} \mathrm{~F}-\mathrm{FDG}$ uptake. We found that patients with overt hypothyroidism had higher L-SUL and BP-SUL and lower M-SUL than individuals with normal thyroid function. These variations in background activity should not be ignored in the interpretations of PET/CT images.

We found that the serum TSH level was an independent predictor of L-SUL. Although TSH might not directly impact liver glucose metabolism, it might have an indirect influence through its effects on other target organs. The TSH receptor (TSHR) is expressed in pancreatic islets, where its activation enhances insulin secretion from $\beta$-cells (17). Insulin can increase cell permeability and stimulate the catalytic actions of enzymes such as glucokinase, glycogen synthetase, and phosphofructokinase in the liver, which in turn increase the rates of glycogen formation and glycolysis in the liver (18-20). Additionally, Lyu et al. showed that TSH increases the level of glucokinase in pancreatic islet $\beta$-cells and directly affects glucose uptake in these cells by upregulating the expression of glucose transporter 2 (GLUT-2) (17). Similar to pancreatic islet $\beta$-cells, hepatocytes also express TSHR, GLUT-2, and glucokinase (17,21-23). Therefore, the same biochemical process observed in pancreatic islet $\beta$-cells might also occur in hepatocytes, which would explain the observed relationship between TSH and L-SUL in our study. Finally, the liver SUL is typically determined by its contained un-phosphorylated ${ }^{18} \mathrm{~F}$-FDG and its ${ }^{18} \mathrm{~F}$-FDG-6phosphate. The former reflects blood FDG concentration. We also found a strong positive correlation between L-SUL and BP-SUL. Thus, the elevated BP-SUL may also partially explain the elevated L-SUL.

There are several potential explanations behind the finding of the positive impact of TSH on BP-SUL. At the cellular level, TSHR is found in erythrocytes, lymphocytes, and granulocytes of the peripheral blood, which might influence metabolic activity $(21,24)$. TSH enhances insulin secretion, which stimulates glucose absorption mediated by sodium-glucose cotransporter 2 in the renal proximal tubules $(25,26)$. As a glucose analog, ${ }^{18} \mathrm{~F}-\mathrm{FDG}$ is transported into the cells and gets trapped there after phosphorylation. In the presence of glucose6-phosphatase, the phosphorylated ${ }^{18} \mathrm{~F}-\mathrm{FDG}$ can be dephosphorylated and released back into the blood (27). At the tissue level, glucose-6-phosphatase is expressed mainly in the liver, where phosphorylated ${ }^{18} \mathrm{~F}$-FDG can be dephosphorylated (28). Therefore, there is a dynamic equilibration between the liver accumulation of ${ }^{18} \mathrm{~F}$-FDG and free ${ }^{18} \mathrm{~F}-\mathrm{FDG}$ in the blood pool.

It has been reported that muscle glucose homeostasis and energy expenditure require the binding of $\mathrm{T} 3$ to thyroid hormone nuclear receptors (29). Hypothyroidism lowers the rate of ATP hydrolysis from muscle glucose metabolism, resulting in decreased heat production by the muscles (30). In individuals with normal thyroid function or hyperthyroidism, insulin promotes the trafficking of GLUT-4 from storage vesicles to the plasma membrane, thus facilitating glucose uptake from the circulation $(18,31,32)$. The expression of GLUT4 in muscle cells is T3 dependent; however, individuals with hypothyroidism are expected to have reduced GLUT4 expression due to decreased levels of serum T3 (29). Also, the reduced rate of 

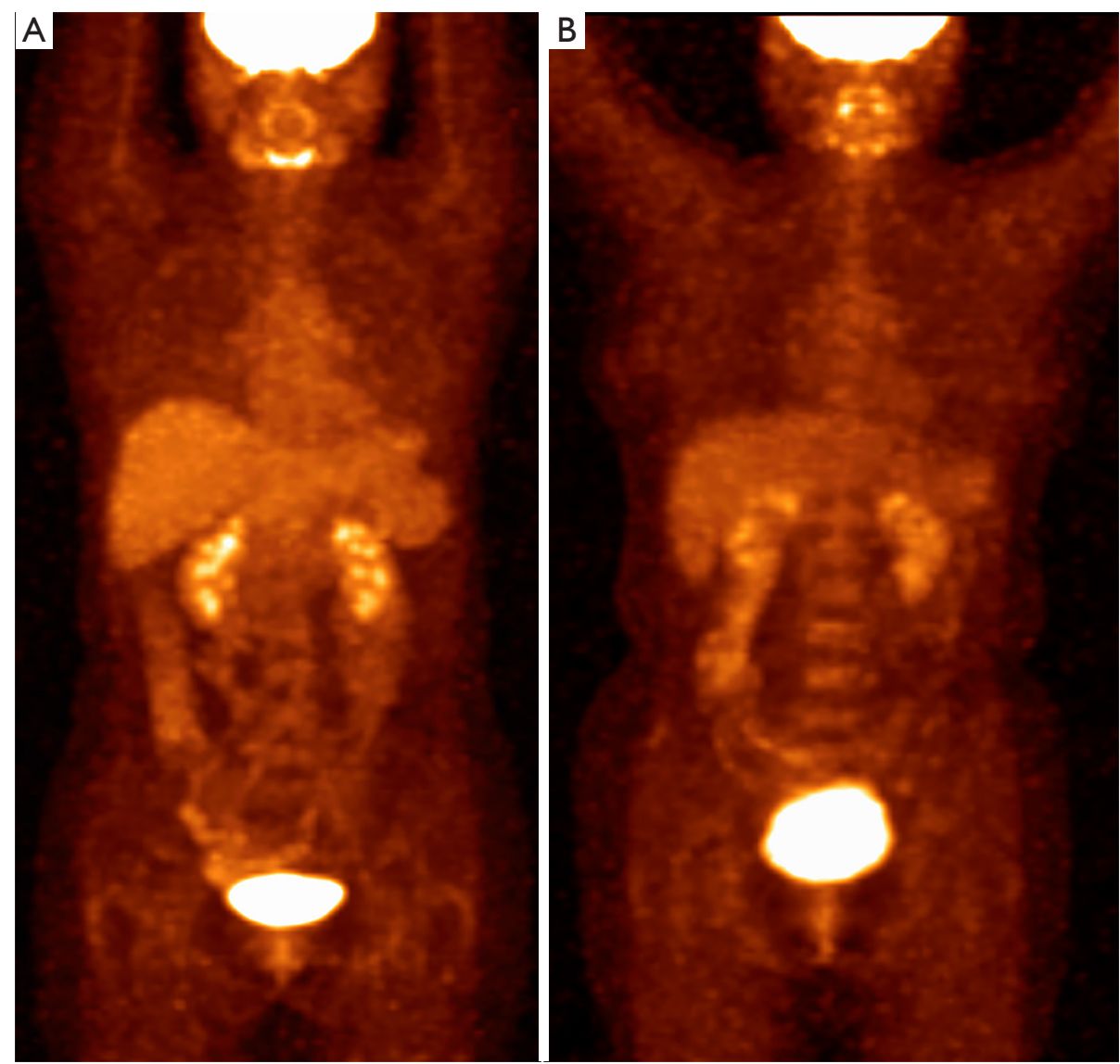

Figure 2 Representative PET maximum intensity projection images of a 37-year-old female patient with hypothyroidism (A) and age and gender-matched control individual (B). The 2 subjects were similar in height (162 and $163 \mathrm{~cm})$, weight (50 and $57 \mathrm{~kg})$, BMI (19.1 and $\left.21.5 \mathrm{~kg} / \mathrm{m}^{2}\right)$, blood glucose level (5.1 and $\left.4.8 \mathrm{mmol} / \mathrm{L}\right), \mathrm{LBM}(34.5$ and $37.7 \mathrm{~kg})$, injected ${ }^{18} \mathrm{~F}-\mathrm{FDG}$ dose $(290$ and $321 \mathrm{MBq})$, and incubation time (64 and $72 \mathrm{~min}$ ). The values for serum TSH (100 and $1.25 \mathrm{mU} / \mathrm{L})$, free triiodothyronine $(1.27$ and $5.17 \mathrm{mU} / \mathrm{L})$, and free thyroxine (2.99 and $13.96 \mathrm{mU} / \mathrm{L}$ ) were typical for hypothyroid and euthyroid status, respectively. The liver and aortic blood-pool SULs were higher in the patient with hypothyroidism (1.52 and 1.02, respectively) than in the control subject (1.19 and 0.77 , respectively). By contrast, the muscle SUL was higher in the control subject (0.44) than in the patient with hypothyroidism (0.41). SUL, standard uptake value normalized by lean body mass; BMI, body mass index; LBM, lean body mass; TSH, serum thyroid-stimulating hormone.

glycolysis caused by hypothyroidism can result in a decrease in the rate of insulin-stimulated glucose utilization (31). For these reasons, glucose uptake is expected to be lower in patients with hypothyroidism than in patients with normal thyroid function or hyperthyroidism. Our results are in line with those of Chen et al., who investigated ${ }^{18} \mathrm{~F}-\mathrm{FDG}$ uptake in patients with hyperthyroidism and found a positive correlation between the serum T3 level and muscle ${ }^{18}$ F-FDG uptake (8).

Adequate repeatability and reproducibility are essential for the evaluation of metabolic response following treatment. It is easy to use the same image acquisition and the same reconstruction parameters on patients with serial examinations or on patients treated with different regimes. However, it is difficult to maintain certain physiological conditions, such as thyroid function, across different time points or multiple patients. Our results suggest that patients with overt hypothyroidism are more prone to false CMR interpretation than patients with normal thyroid function because of the metabolic response criteria and the increased liver and blood-pool activities associated with overt hypothyroidism (1-3). Hence, knowledge of the impact of thyroid function on background activities is important for accurate response interpretation and for response comparisons among different therapeutic regimes.

The main limitation of our study was the relatively 
Table 3 Significant bivariate correlations between background SULs and other patient factors

\begin{tabular}{|c|c|c|}
\hline Significant factors & Coefficient & $P$ value \\
\hline Gender (male: 1, female: 0) & 0.607 & $<0.001$ \\
\hline Height & 0.502 & $<0.001$ \\
\hline Weight & 0.417 & $<0.001$ \\
\hline LBM $^{*}$ & 0.600 & $<0.001$ \\
\hline $\mathrm{TSH}^{*}$ & 0.302 & 0.010 \\
\hline \multicolumn{3}{|l|}{ BP-SUL } \\
\hline Gender (male: 1, female: 0) & 0.524 & $<0.001$ \\
\hline${ }^{18}$ F-FDG dose & 0.423 & $<0.001$ \\
\hline Incubation time ${ }^{*}$ & -0.354 & 0.002 \\
\hline LBM $^{*}$ & 0.519 & $<0.001$ \\
\hline $\mathrm{TSH}^{*}$ & 0.299 & 0.011 \\
\hline \multicolumn{3}{|l|}{ M-SUL } \\
\hline Gender (male: 1 , female: 0) & 0.421 & $<0.001$ \\
\hline Height & 0.428 & $<0.001$ \\
\hline LBM $^{*}$ & 0.325 & 0.005 \\
\hline
\end{tabular}

Factors labeled with * are Spearman correlations, because they were non-normal variables. The other factors were Pearson correlations. LBM, lean body mass; TSH, serum thyroid-stimulating hormone; FT3, serum free triiodothyronine; FT4, serum free thyroxine; L-SUL, liver normalized standard uptake value; BP-SUL, aortic blood-pool normalized standard uptake value, M-SUL, muscle normalized standard uptake value.

small sample size. The patients we selected all had severe iatrogenic hypothyroidism due to total thyroidectomy or radioiodine therapy, which might increase the statistical bias, and the results of our study may not be generalizable to mild hypothyroidism. Furthermore, we did not analyze whether tumor burden was one of the impact factors for the SULs in the overt hypothyroidism group. Viglianti et al. demonstrated that tumor burden harms these sites' FDG uptake due to the FDG reservoir or sink effect (33). According to this, much higher liver and bloodpool activities could be expected in the hypothyroid patient if there was no FDG avid tumor. Unlike in the prior study, none of the participants had multiple ${ }^{18} \mathrm{~F}$-FDG PET/CT scans taken at times when their thyroid status was different, so it was not possible to make intrapatient comparisons between hypothyroid and euthyroid statuses (8). Also, we could not accurately measure serum TSH values higher than $100 \mathrm{mU} / \mathrm{L}$ because of a methodological issue, which might have affected our determination of the best predictors of different background SULs.

Despite the limitations, our results still indicated that overt hypothyroidism increased liver and blood-pool ${ }^{18} \mathrm{~F}$-FDG uptake and decreased skeletal muscle ${ }^{18} \mathrm{~F}$-FDG uptake compared with euthyroid individuals. We believe that overt abnormal thyroid function should be cured in patients who require metabolic response evaluation by ${ }^{18}$ F-FDG PET/CT. The possibility of false-positive/falsenegative results should be taken into account for those 

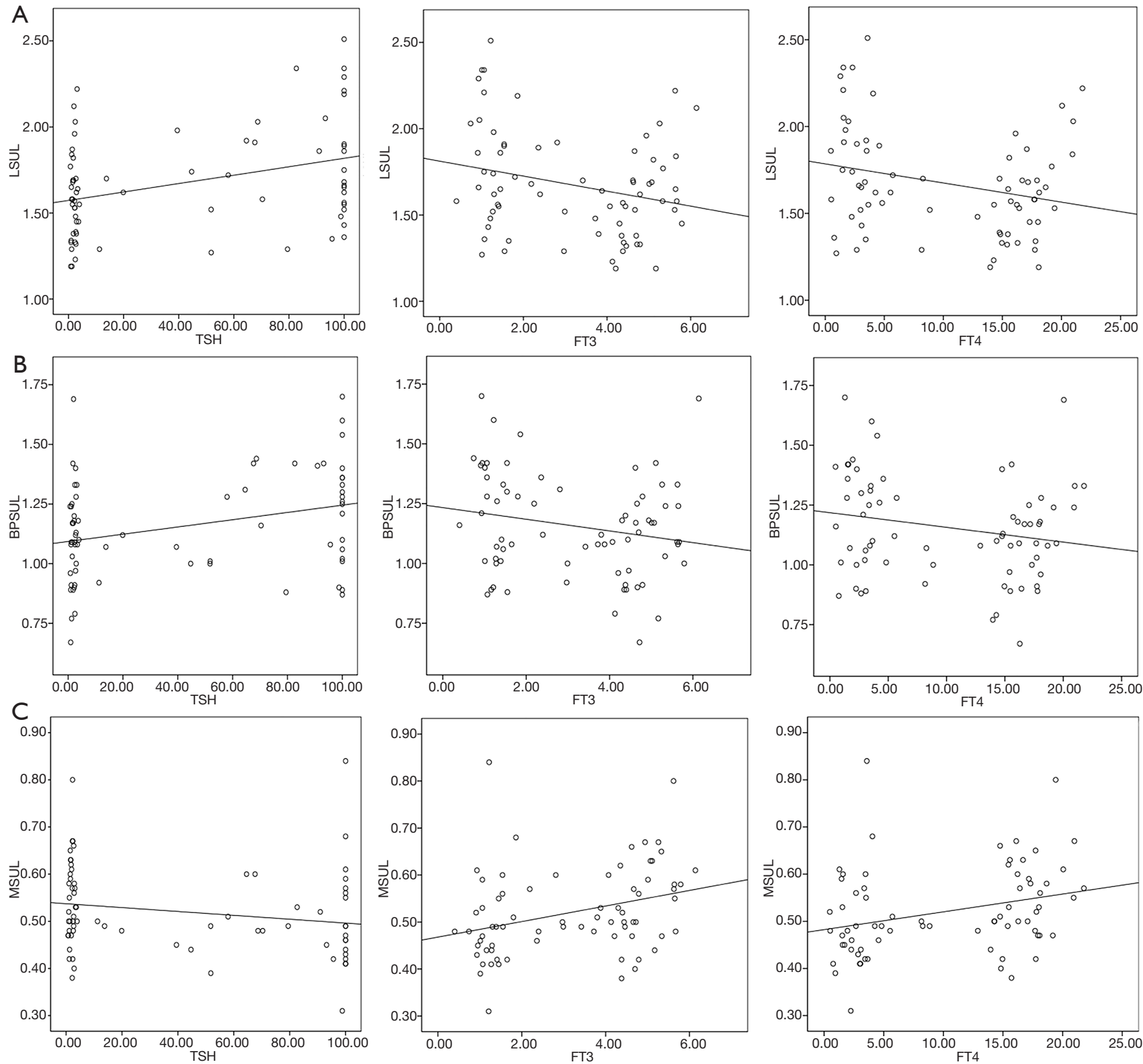

Figure 3 The correlations between thyroid function and the SULs on 18F-FDG PET/CT by Spearman's rank analysis. L-SUL (A) and BP-SUL (B) directly correlated with TSH levels (rho =0.302 and 0.299, both $\mathrm{P}<0.05$ ). (C) M-SUL directly correlated with FT3 levels (rho $=0.376, \mathrm{P}<0.05)$. SUL, standard uptake value normalized by lean body mass; TSH, serum thyroid-stimulating hormone; FT3, serum free triiodothyronine; FT4, serum free thyroxine; L-SUL, liver normalized standard uptake value; BP-SUL, aortic blood-pool normalized standard uptake value, M-SUL, muscle normalized standard uptake value. 
Table 4 Independent predictors of background SULs in the multivariate analysis

\begin{tabular}{|c|c|c|c|c|c|c|}
\hline Independent factors & \multicolumn{2}{|c|}{ Unstandardized coefficients } & $\begin{array}{c}\text { Standardized } \\
\text { coefficients, beta value }\end{array}$ & T value & $95 \% \mathrm{Cl}$ & $P$ value \\
\hline \multicolumn{7}{|l|}{ L-SUL } \\
\hline Constant & 1.408 & 0.043 & - & 33.031 & $1.323-1.493$ & $<0.001$ \\
\hline Gender* & 0.371 & 0.052 & 0.609 & 7.115 & $0.267-0.475$ & $<0.001$ \\
\hline$R^{2}$ & & 0.495 & & & & \\
\hline \multicolumn{7}{|l|}{ BP-SUL } \\
\hline Constant & 1.010 & 0.113 & - & 8.933 & $0.784-1.236$ & $<0.001$ \\
\hline Gender* & 0.243 & 0.037 & 0.567 & 6.516 & $0.169-0.318$ & $<0.001$ \\
\hline TSH & 0.001 & 0.000 & 0.288 & 3.332 & $0.001-0.002$ & 0.001 \\
\hline $\mathrm{R}^{2}$ & & 0.504 & & & & \\
\hline \multicolumn{7}{|l|}{ M-SUL } \\
\hline Constant & -0.654 & 0.206 & - & -3.176 & -1.066 to -0.243 & 0.002 \\
\hline Height & 0.006 & 0.001 & 0.523 & 5.191 & $0.004-0.008$ & $<0.001$ \\
\hline Age & 0.003 & 0.001 & 0.349 & 3.464 & $0.001-0.005$ & 0.001 \\
\hline FT3 & 0.016 & 0.005 & 0.310 & 3.234 & $0.006-0.026$ & 0.002 \\
\hline $\mathrm{R}^{2}$ & & 0.379 & & & & \\
\hline
\end{tabular}

*, male was assigned as 1 and female was assigned as $0 . \mathrm{R}^{2}$, R-square value for the best-fit model using stepwise multivariate analysis; TSH, serum thyroid-stimulating hormone; FT3, serum free triiodothyronine; L-SUL, liver normalized standard uptake value; BP-SUL, aortic blood-pool normalized standard uptake value; M-SUL, muscle normalized standard uptake value.

who cannot recover thyroid function completely. Because the influence of thyroid function on glucose metabolism is systemic, it may also affect other organs. Whether there is a more suitable background region requires further study. Additionally, recombinant human TSH injection before ${ }^{18}$ F-FDG PET/CT may have a similar effect, although thyroid hormone levels are not significantly changed. Finally, for further validation of our results, studies with larger sample sizes will be required, and diverse hypothyroidism levels should be included.

\section{Conclusions}

PET/CT scans showed a pattern of increased ${ }^{18} \mathrm{~F}-\mathrm{FDG}$ uptake in the liver and blood pool and decreased ${ }^{18} \mathrm{~F}$-FDG uptake in the skeletal muscle in patients with hypothyroidism. The magnitude of the alterations in
${ }^{18}$ F-FDG uptake corresponded to the severity of the hypothyroidism. Overt abnormal thyroid function should be noted before PET/CT is used to determine a cancer treatment's metabolic response.

\section{Acknowledgments}

Funding: This work was supported by the Sichuan Provincial Department of Science and Technology support program (2015SZ0128) and National Key Research and Development Program of China during the "13th Five-year Plan" (2016YFC0104300).

\section{Footnote}

Conflicts of Interest: All authors have completed the ICMJE uniform disclosure form (available at http://dx.doi. 
org/10.21037/qims-20-1310). The authors have no conflicts of interest to declare.

Ethical Statement: The authors are accountable for all aspects of the work in ensuring that questions related to the accuracy or integrity of any part of the work are appropriately investigated and resolved. This study was approved by the Institutional Review Board of the West China Hospital and was conducted according to the Declaration of Helsinki guidelines (as revised in 2013). The requirement to obtain written, informed patient consent was waived because the study was retrospective.

Open Access Statement: This is an Open Access article distributed in accordance with the Creative Commons Attribution-NonCommercial-NoDerivs 4.0 International License (CC BY-NC-ND 4.0), which permits the noncommercial replication and distribution of the article with the strict proviso that no changes or edits are made and the original work is properly cited (including links to both the formal publication through the relevant DOI and the license). See: https://creativecommons.org/licenses/by-nc-nd/4.0/.

\section{References}

1. Wahl RL, Jacene H, Kasamon Y, Lodge MA. From RECIST to PERCIST: Evolving Considerations for PET response criteria in solid tumors. J Nucl Med 2009;50 Suppl 1:122s-50s.

2. Marcus C, Ciarallo A, Tahari AK, Mena E, Koch W, Wahl RL, Kiess AP, Kang H, Subramaniam RM. Head and neck PET/CT: therapy response interpretation criteria (Hopkins Criteria)-interreader reliability, accuracy, and survival outcomes. J Nucl Med 2014;55:1411-6.

3. Barrington SF, Mikhaeel NG, Kostakoglu L, Meignan M, Hutchings M, Mueller SP, Schwartz LH, Zucca E, Fisher RI, Trotman J, Hoekstra OS, Hicks RJ, O'Doherty MJ, Hustinx R, Biggi A, Cheson BD. Role of imaging in the staging and response assessment of lymphoma: consensus of the International Conference on Malignant Lymphomas Imaging Working Group. J Clin Oncol 2014;32:3048-58.

4. Adams MC, Turkington TG, Wilson JM, Wong TZ. A systematic review of the factors affecting accuracy of SUV measurements. AJR Am J Roentgenol 2010;195:310-20.

5. Chiaravalloti A, Danieli R, Abbatiello P, Di Pietro B, Travascio L, Cantonetti M, Guazzaroni M, Orlacchio A, Simonetti G, Schillaci O. Factors affecting intrapatient liver and mediastinal blood pool 18F-FDG standardized uptake value changes during ABVD chemotherapy in Hodgkin's lymphoma. Eur J Nucl Med Mol Imaging 2014;41:1123-32.

6. Ceriani L, Suriano S, Ruberto T, Zucca E, Giovanella L. 18F-FDG uptake changes in liver and mediastinum during chemotherapy in patients with diffuse large B-cell lymphoma. Clin Nucl Med 2012;37:949-52.

7. Cao Y, Zhou K, Diao W, Long X, Tian F, Su M, Jia Z. Age-related changes of standardized uptake values in the blood pool and liver: a decade-long retrospective study of the outcomes of 2,526 subjects. Quant Imaging Med Surg 2021;11:95-106.

8. Chen YK, Chen YL, Tsui CC, Wang SC, Cheng RH. The significance of alteration 2-[fluorine-18]fluoro2-deoxy-(D)-glucose uptake in the liver and skeletal muscles of patients with hyperthyroidism. Acad Radiol 2013;20:1218-23.

9. Kim MH, Kim DW, Park SA, Kim CG. Transiently Altered Distribution of F-18 FDG in a Patient with Subacute Thyroiditis. Nucl Med Mol Imaging 2018;52:82-4.

10. Chen YK, Wang YF, Chiu JS. Diagnostic trinity: Graves' disease on F-18 FDG PET. Clin Nucl Med 2007;32:816-7.

11. Taylor PN, Albrecht D, Scholz A, Gutierrez-Buey G, Lazarus JH, Dayan CM, Okosieme OE. Global epidemiology of hyperthyroidism and hypothyroidism. Nat Rev Endocrinol 2018;14:301-16.

12. Chaker L, Bianco AC, Jonklaas J, Peeters RP. Hypothyroidism. Lancet 2017;390:1550-62.

13. Pil J, Nevens D, Van der Vorst A, Gadan C, Nuyts S. The incidence of hypothyroidism after radiotherapy for head and neck cancer. B-ENT 2016;12:257-62.

14. Mullur R, Liu YY, Brent GA. Thyroid hormone regulation of metabolism. Physiol Rev 2014;94:355-82.

15. Boellaard R, Delgado-Bolton R, Oyen WJ, Giammarile F, Tatsch K, Eschner W, Verzijlbergen FJ, Barrington SF, Pike LC, Weber WA, Stroobants S, Delbeke D, Donohoe KJ, Holbrook S, Graham MM, Testanera G, Hoekstra OS, Zijlstra J, Visser E, Hoekstra CJ, Pruim J, Willemsen A, Arends B, Kotzerke J, Bockisch A, Beyer T, Chiti A, Krause BJ. FDG PET/CT: EANM procedure guidelines for tumour imaging: version 2.0. Eur J Nucl Med Mol Imaging 2015;42:328-54.

16. Barrington SF, Johnson PWM. (18)F-FDG PET/CT in Lymphoma: Has Imaging-Directed Personalized Medicine Become a Reality? J Nucl Med 2017;58:1539-44.

17. Lyu J, Imachi H, Yoshimoto T, Fukunaga K, Sato S, Ibata 
T, Kobayashi T, Dong T, Yonezaki K, Yamaji N, Kikuchi F, Iwama H, Ishikawa R, Haba R, Sugiyama Y, Zhang $\mathrm{H}$, Murao K. Thyroid stimulating hormone stimulates the expression of glucose transporter 2 via its receptor in pancreatic beta cell line, INS-1 cells. Sci Rep 2018;8:1986.

18. Petersen MC, Shulman GI. Mechanisms of Insulin Action and Insulin Resistance. Physiol Rev 2018;98:2133-223.

19. Lenzen S. A fresh view of glycolysis and glucokinase regulation: history and current status. J Biol Chem 2014;289:12189-94.

20. Ramnanan CJ, Edgerton DS, Rivera N, IrimiaDominguez J, Farmer B, Neal DW, Lautz M, Donahue EP, Meyer CM, Roach PJ, Cherrington AD. Molecular characterization of insulin-mediated suppression of hepatic glucose production in vivo. Diabetes 2010;59:1302-11.

21. Williams GR. Extrathyroidal expression of TSH receptor. Ann Endocrinol (Paris) 2011;72:68-73.

22. Thorens B. GLUT2, glucose sensing and glucose homeostasis. Diabetologia 2015;58:221-32.

23. Matschinsky FM. Glucokinase as glucose sensor and metabolic signal generator in pancreatic beta-cells and hepatocytes. Diabetes 1990;39:647-52.

24. Balazs C, Bokk A, Kiss E. Inhibition of metabolic activity of polymorphonuclear granulocytes by thyroid stimulating antibodies. J Endocrinol Invest 1992;15:465-9.

25. Nakamura N, Matsui T, Ishibashi Y, Yamagishi S. Insulin stimulates SGLT2-mediated tubular glucose absorption via oxidative stress generation. Diabetol Metab Syndr $2015 ; 7: 48$.

Cite this article as: Yang P, Fan Q, Cai H, Tian R, Su M. The effect of hypothyroidism on referential background metabolic activity on ${ }^{18}$ F-FDG PET/CT. Quant Imaging Med Surg 2021;11(8):3666-3676. doi: 10.21037/qims-20-1310
26. Singh S, Sharma R, Kumari M, Tiwari S. Insulin receptors in the kidneys in health and disease. World J Nephrol 2019;8:11-22.

27. Maschauer S, Prante O, Hoffmann M, Deichen JT, Kuwert T. Characterization of 18F-FDG uptake in human endothelial cells in vitro. J Nucl Med 2004;45:455-60.

28. van Schaftingen E, Gerin I. The glucose-6-phosphatase system. Biochem J 2002;362:513-32.

29. Salvatore D, Simonides WS, Dentice M, Zavacki AM, Larsen PR. Thyroid hormones and skeletal muscle--new insights and potential implications. Nat Rev Endocrinol 2014;10:206-14.

30. Leijendekker WJ, van Hardeveld C, Elzinga G. Heat production during contraction in skeletal muscle of hypothyroid mice. Am J Physiol 1987;253:E214-20.

31. Dimitriadis G, Parry-Billings $M$, Bevan S, Leighton B, Krause U, Piva T, Tegos K, Challiss RA, Wegener G, Newsholme EA. The effects of insulin on transport and metabolism of glucose in skeletal muscle from hyperthyroid and hypothyroid rats. Eur J Clin Invest 1997;27:475-83.

32. Leto D, Saltiel AR. Regulation of glucose transport by insulin: traffic control of GLUT4. Nat Rev Mol Cell Biol 2012;13:383-96.

33. Viglianti BL, Wale DJ, Wong KK, Johnson TD, Ky C, Frey KA, Gross MD. Effects of Tumor Burden on Reference Tissue Standardized Uptake for PET Imaging: Modification of PERCIST Criteria. Radiology 2018;287:993-1002. 


\section{Supplementary}

Table S1 The comparation of the season and outside max/min temperature on scanning day between the two groups

\begin{tabular}{|c|c|c|c|c|}
\hline & Hypothyroid, $n=36$ & Euthyroid, $n=36$ & $t / \chi^{2}$ & $P$ value \\
\hline Spring & $7(19.4)$ & $11(30.6)$ & & \\
\hline Summer & $8(22.2)$ & $11(30.6)$ & & \\
\hline Autumn & $15(41.7)$ & $8(22.2)$ & & \\
\hline Maximum temperature $\left({ }^{\circ} \mathrm{C}\right)$ & & & -0.317 & 0.752 \\
\hline Mean \pm SD & $22.33 \pm 6.71$ & $22.88 \pm 8.10$ & & \\
\hline Range & $9-33$ & $8-33$ & & \\
\hline Minimum temperature $\left({ }^{\circ} \mathrm{C}\right)$ & & & -0.682 & 0.498 \\
\hline
\end{tabular}

$\mathrm{P}$ values were determined by two independent sample $t$ test and Chi-square test between the patients with hypothyroidism and the controls.

Table S2 Bivariate correlations between background SULs and season and outside max/min temperature on scanning day

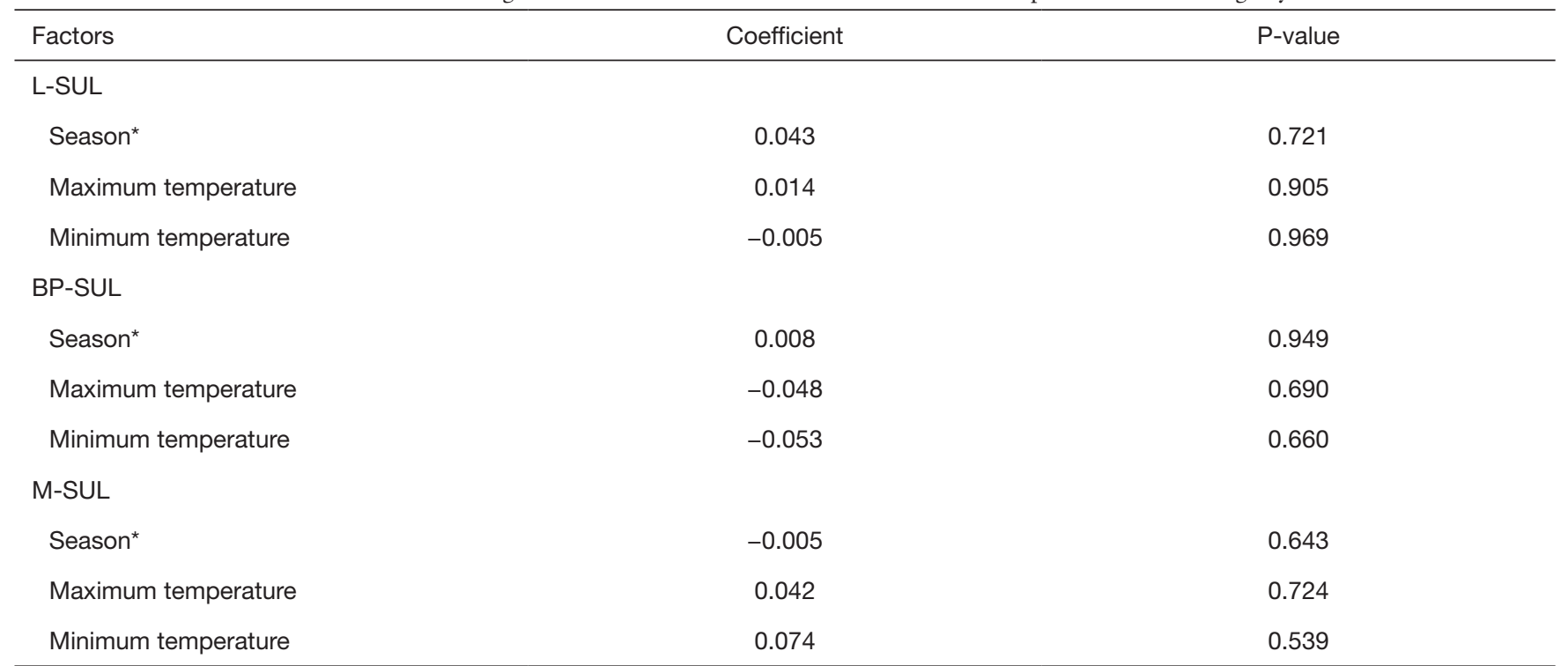

Factors labeled with * are Spearman correlations, because they were non-normal variables. The other factors were Pearson correlations. L-SUL, liver normalized standard uptake value; BP-SUL, aortic blood-pool normalized standard uptake value, M-SUL, muscle normalized standard uptake value. 